\title{
Xanthene[n]arenes: Exceptionally Large, Bowl-Shaped Macrocyclic Building Blocks Suitable for Self-Assembly
}

\author{
Jonathan Pfeuffer-Rooschüz, Lucius Schmid, Alessandro Prescimone, and Konrad Tiefenbacher* \\ Cite This: JACS Au 2021, 1, 1885-1891 \\ Read Online
}

ACCESS

Lلll Metrics \& More

Article Recommendations

Supporting Information

ABSTRACT: A new class of macrocycles denoted as "xanthene $[n]$ arenes" was synthesized. In contrast to most other macrocycles, they feature a conformationally restricted bowl shape due to the attached alkyl groups at the linking methylene units. This facilitates the synthesis of cavitands and the selfassembly to molecular capsules via noncovalent interactions. The derivatization potential of the novel macrocycles was demonstrated on the xanthene[3] arene scaffold. Besides a deep cavitand and an oxygen-embedded zigzag hydrocarbon belt[12] arene, a modified macrocycle was synthesized that self-assembles into a hydrogen-bonded tetrameric capsule, demonstrating the potential of xanthene $[n]$ arenes as a new set of macrocyclic building blocks.

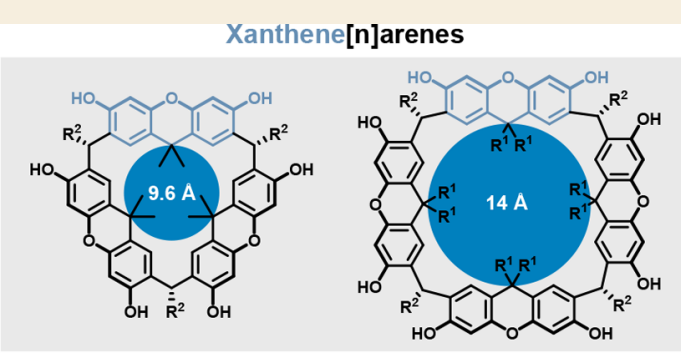

- Large, conform. restricted, bowl-shaped macrocycles - Inner diameter of 9.6 and $14 \mathrm{~A}$

- Derivatization: cavitand, capsule, hydrocarbon belt

KEYWORDS: macrocycle, macrocyclization, self-assembly, molecular capsule, host-guest chemistry, calixarene, hydrocarbon belt, deep cavitand

$\mathrm{M}$ acrocycles have been a cornerstone in supramolecular chemistry since its beginning, which was marked by the discovery of crown ethers. ${ }^{1,2}$ A wide variety of macrocycles featuring different degrees of conformational freedom and sizes has been developed and explored intensively ever since. ${ }^{3-10}$ An important subset of these macrocycles is comprised of conformationally restricted bowl-shaped derivatives, which are required for the construction of cavitands ${ }^{11,12}$ and closed host structures like (hemi)carcerands. ${ }^{5,6,13-17}$ Moreover, the self-assembly of molecular capsules via noncovalent interactions depends on such bowl-shaped macrocycles. ${ }^{18-24}$ Macrocycles utilized for self-assemblies mainly comprise phenol-based systems like the calixarene family of compounds, ${ }^{25-27}$ with the two widely used members resorcinarene (1, Figure 1a) and pyrogallolarene (2). ${ }^{28}$ The key features of these bowl-shaped molecules are (1) the crown conformation is highly favored due to the preference of the $\mathrm{R}$ substituents for the axial orientation and the hydrogen bond pattern of the free phenols $^{28}$ and (2) the $\mathrm{R}$ residues are essential for increasing the solubility of the free phenol compounds. This enhanced solubility facilitates self-assembly processes via hydrogen bonds and the facile derivatization of the macrocycles as low solubility is often a challenge for synthetic work. ${ }^{29}$ Naturally, it was attempted to broaden this specific subclass of macrocycles by replacing the benzene-based building blocks with larger ones, for instance, naphthalene-derived ones. Unfortunately, all attempts have failed to deliver size-extended bowl-shaped resorcinarene-like macrocycles as of yet. ${ }^{30-33}$ During the past decade, many new large phenol-based macrocycles, including 3-8 (Figure 1b), ${ }^{34-41}$ have been reported. ${ }^{42-48}$ Importantly, in contrast to $\mathbf{1}$ and $\mathbf{2}$, they do not feature $\mathrm{R}$ residues at the linking methylene units that conformationally restrict the crown conformation, and increase the solubility of the free phenol derivatives. The higher conformational freedom of the $\mathrm{CH}_{2}$-linked macrocycles is revealed in the ${ }^{1} \mathrm{H}$ NMR spectra. For instance, the calix[n] carbazoles (6) and the fluoren[3]arenes (7) feature magnetically equivalent hydrogens at the methylene linkages. Such a high symmetry originates from a fast inversion of the macrocyclic ring. In contrast, macrocycles 1 and $\mathbf{2}$ feature a conformationally restricted bowl shape that does not invert due to the presence of the $\mathrm{R}$ substituents.

Studies on the resorcinarene framework have furthermore demonstrated that the synthetic access to methylene-linked systems is more facile than the R-substituted ones, giving more facile access to the unsubstituted larger penta-, hexa-, and heptameric resorcinarenes. ${ }^{49-53}$ This might explain the prevalence of methylene-linked macrocycles over R-substituted ones (Figure 1).

Herein, we report the synthesis of new, exceptionally large, conformationally restricted bowl-shaped macrocycles X-3 and $\mathrm{X}-4$ (Figure 1c), composed of three or four xanthene units, respectively, and propose the name "xanthene $[n]$ arenes" (X-n). In contrast to the known large macrocycles (Figure $1 \mathrm{~b}$ ), they

Received: August 6, 2021

Published: October 19, 2021

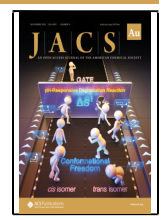


(a) Conformationally restricted, bowl-shaped macrocycles $H$

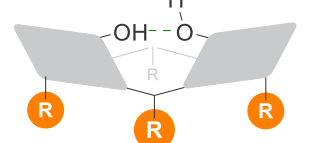

- conform. restricted bowl

- due to R, good solubility of free phenol compound

- suitable for capsular selfassembly

- few examples<smiles>[X]c1c(O)c(C)cc(C(C)(C)C)c1O</smiles>

Resorcin[4]arenes $\mathrm{X}=\mathrm{H}$ (1) Pyrogallol[4]arenes $\mathrm{X}=\mathrm{OH}(2)$ (b) Large macrocycles

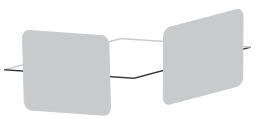

- different conformations

- conformationally flexible

- low solubility of free phenol compound

- not suitable for capsular self-assembly

- several examples

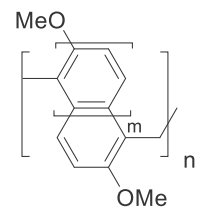

Prism[n]arenes $(m=1)(3)$

Pagoda[n]arenes $(m=2)(4)$<smiles></smiles>

Calix[n]carbazoles $\left(X=N R^{2}\right)(6)$

Fluoren[3]arenes $\left(X=\mathrm{CR}^{2}{ }_{2}\right)(7)$

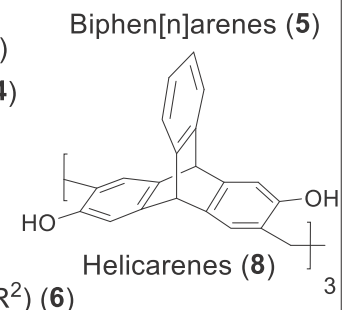

Biphen[n]arenes (5)

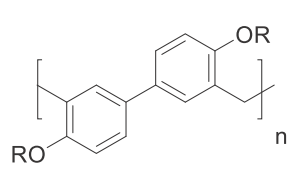

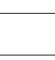

(c) This work: Large and conformationally restricted

Bowl-shaped Macrocycles: Xanthene[n]arenes (X-n)

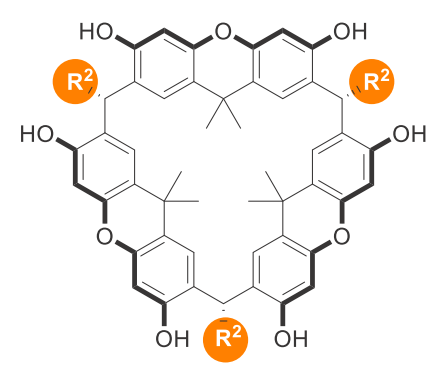

Xanthene[3]arenes $(\mathbf{X}-\mathbf{3})$

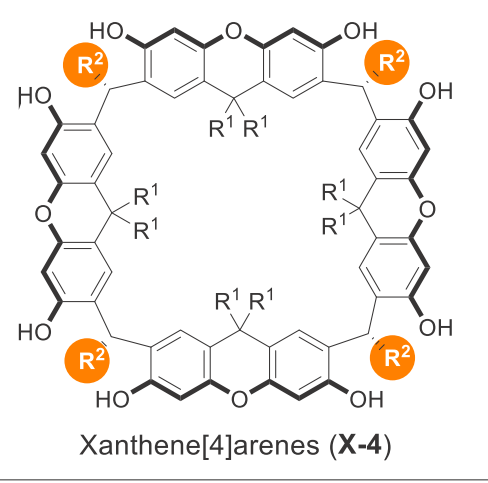

Figure 1. Xanthene $[n]$ arenes extend the narrow field of conformationally restricted, bowl-shaped macrocycles as its largest representative.

carry $\mathrm{R}$ residues on the linking methylene units and, therefore, feature the two main advantages mentioned in the introduction: (1) the conformationally restricted crown conformation and (2) the good solubility of the free phenol compounds. We demonstrate that they are well-suited for the construction of deeper cavitands, hydrocarbon belts, and the self-assembly of hydrogen bond-based molecular capsules.

The known xanthene 9 can easily be obtained on the decagram scale from acetone and resorcinol in the presence of the Lewis acid $\mathrm{ZnCl}_{2}$ (Scheme 1). ${ }^{54}$ In analogy to the calixarene/resorcinarene syntheses, a direct macrocyclization of 9 and different aldehydes under acidic conditions was attempted. However, no traces of xanthene $[n]$ arenes were detected via ${ }^{1} \mathrm{H}$ NMR and ESI-MS analysis. Therefore, we decided to attempt macrocyclization in a head-to-tail manner from the prefunctionalized monomer 15 equipped with the side chain and the reactive benzylic alcohol moiety.
Compound $\mathbf{1 5}$ is accessible via a simple four-step procedure. After benzyl protection in high yield (92\%), selective monoformylation was achieved using Vilsmeier-Haack conditions in excellent yield (96\%).

Subsequently, the benzyl groups were removed using TFA to deliver aldehyde 12 (62\%). Finally, Grignard-addition yielded the desired benzylic alcohol 15 (90\%). Extensive screening of cyclization conditions using different acids, solvents, and concentrations resulted in very low yields $(<5 \%)$ of the macrocyclic products in most cases (see Supporting Information, Chapter 3). Gratifyingly, under optimized conditions ( $25 \mathrm{mM} \mathrm{15,15}$ vol \% TFA: $\mathrm{CH}_{2} \mathrm{Cl}_{2}, 20$ $\mathrm{h}, 0{ }^{\circ} \mathrm{C}$ to $\mathrm{rt}$ ), the xanthene[3] arene 19 was obtained as the major macrocyclic product in $21 \%$ isolated yield. The even larger X-4 was only observed in traces via MALDI-MS. Attempts to increase the amount of $\mathrm{X}-4$ by changing the reaction conditions failed. We speculated that the product 
Scheme 1. Synthesis of Xanthene $[n]$ arenes 19-22

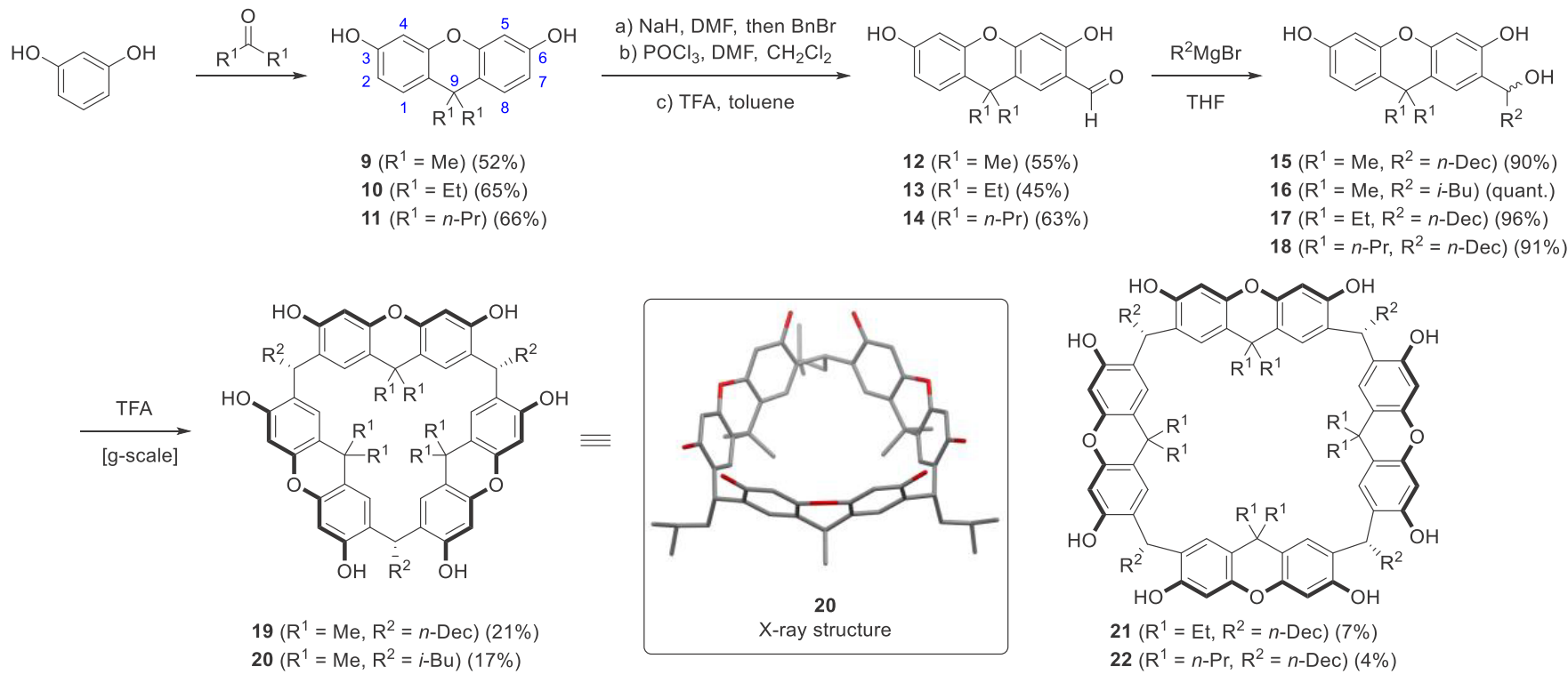

Scheme 2. Derivatization of the Xanthene[3] arene Scaffold $^{a}$

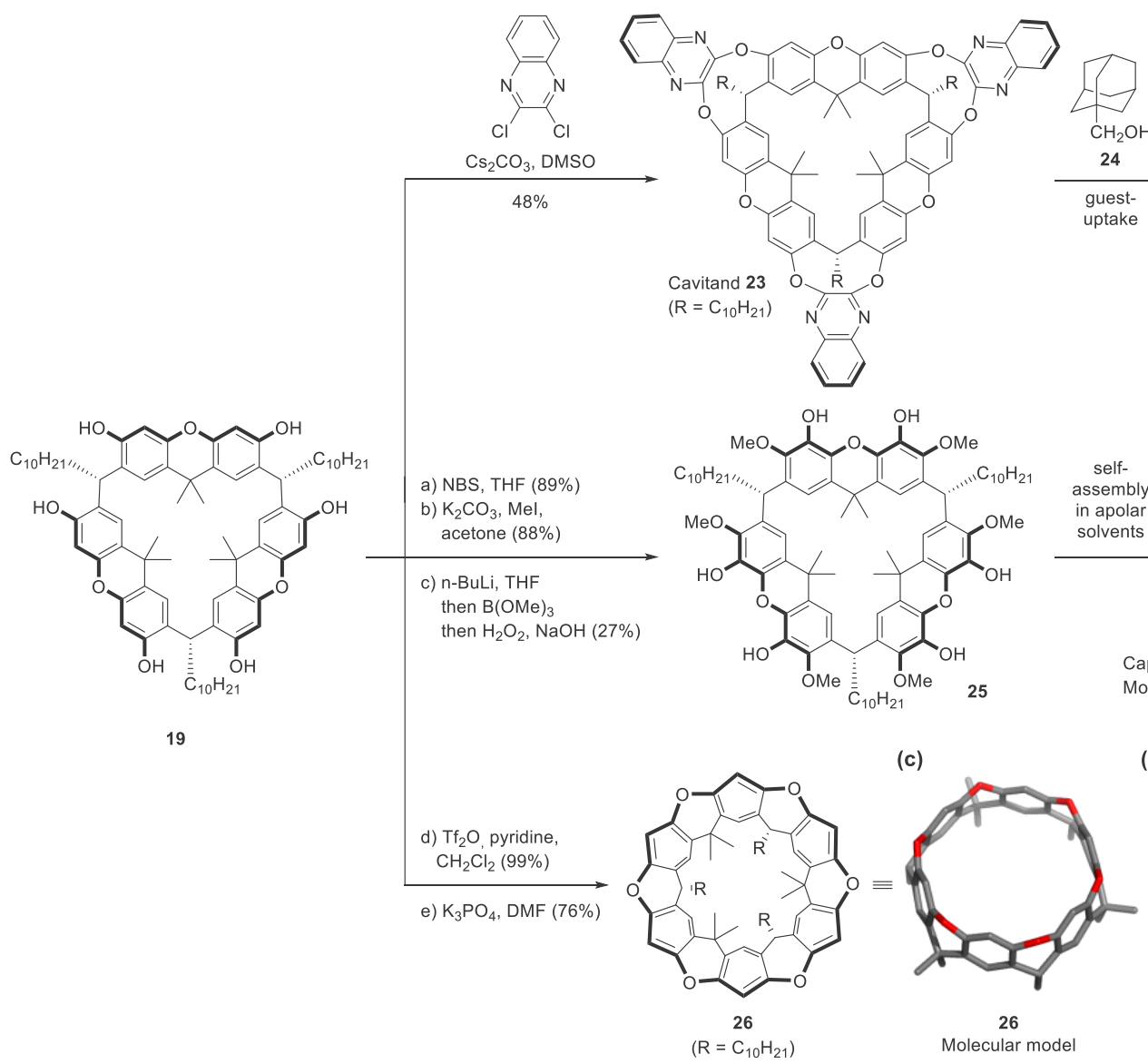

(a)

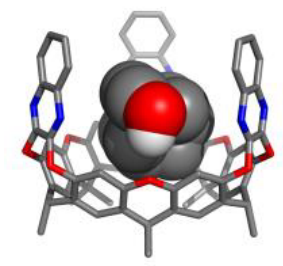

(b)

$23 \subset 24$

Molecular model

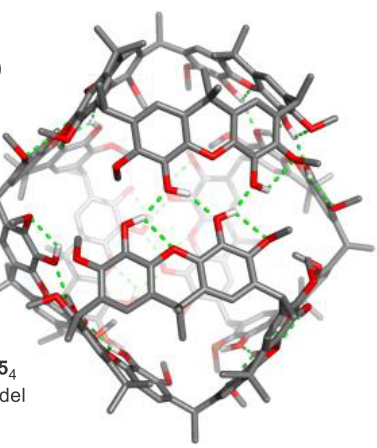

apsule I $=\mathbf{2 5}_{\mathbf{4}}$ Molecular mode

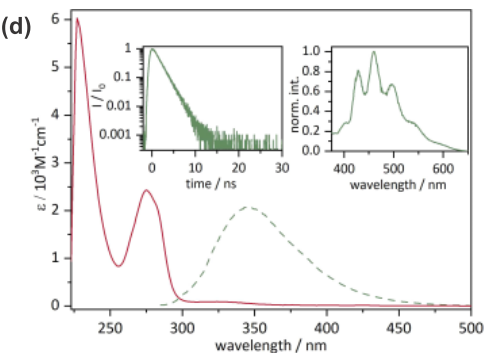

${ }^{a}$ Molecular models of complex $23 \subset \mathbf{2 4}$ (a), the self-assembled tetrameric capsule I (b), and the $\mathrm{O}_{6}$-belt[12]arene 26 (c). (d) Main plot: UV-vis absorption (solid red line) and normalized luminescence spectrum (dashed green line) of 26 recorded in dry, deaerated $\mathrm{CH}_{2} \mathrm{Cl}_{2}$ at $293 \mathrm{~K}$. Left inset: Luminescence decay detected at $350 \mathrm{~nm}$ of $2 \times 10^{-5} \mathrm{M} 26$ in dry, deaerated $\mathrm{CH}_{2} \mathrm{Cl}_{2}$ at $293 \mathrm{~K}$ following excitation at $313 \mathrm{~nm}$ with laser pulses of $\sim 60$ ps duration. Right inset: Luminescence spectrum of $10^{-5} \mathrm{M} 26$ recorded at $77 \mathrm{~K}$ in 2-methyl-THF. For the steady-state luminescence measurements, excitation occurred at $275 \mathrm{~nm}$.

distribution might be shifted toward the larger $\mathrm{X}-4$ by the installation of larger $\mathrm{R}^{1}$ groups that might prevent $\mathrm{X}-3$ formation sterically. The ethyl- and n-propyl-xanthenes $\mathbf{1 0}$ and 11 were obtained on gram scale from resorcinol and the 
corresponding ketone using hydrochloric acid instead of the zinc chloride utilized for 9. They were converted to the benzylic alcohols 17 and 18 in good yields utilizing the chemistry developed for $\mathbf{1 5}$. Indeed, utilizing the cyclization conditions optimized for the conversion of 15 to 19, conversion of 17 and $\mathbf{1 8}$ led to the tetrameric X-4 structures 21 and 22 as the only defined cyclization products, albeit in very low yields $(<1 \%)$. Although the yield was terrible, the selective formation of $\mathrm{X}-4$ over $\mathrm{X}-3$ was promising. Furthermore, it was found that the product X-4 decomposes during the extended reaction time $(20 \mathrm{~h})$. After extensive optimizations, shorter and milder reaction conditions were found (64 mM 17/18, 1:9 TFA:DCE, $60 \mathrm{~min}, 0{ }^{\circ} \mathrm{C}$ ) that yielded the X-4-derivatives $\mathbf{2 1}$ and $\mathbf{2 2}$ in at least useful yields of 7 and 4\%, respectively (see Supporting Information, Chapter 4).

All macrocycles synthesized (19, 21, and 22) were characterized by ${ }^{1} \mathrm{H}$-, ${ }^{13} \mathrm{C}$-, and $2 \mathrm{D}-\mathrm{NMR}$ spectroscopy as well as ESI-HRMS measurements. Additionally, the crystalline xanthene[3] arene derivative 20, featuring $i$-Bu instead of $n$-Dec feet, was synthesized via alcohol 16. Single crystals suitable for $\mathrm{X}$-ray crystallography were obtained by slow evaporation of a solution of $\mathbf{2 0}$ in THF. The crystal structure analysis of $\mathbf{2 0}$ (space group: $P 4 / n)$ confirms the crown conformation $\left(\mathrm{C}_{3 \mathrm{~V}^{-}}\right.$ symmetry, Scheme 1). While the tetrahedral angles between two adjacent xanthene units remain at $109.4^{\circ}$, interestingly, the dihedral angles between the two aromatic units of each xanthene are $16.5^{\circ}$, induced by the strain of the macrocycle.

To demonstrate that these unusually large, conformationally restricted, bowl-shaped macrocycles indeed feature the same advantages as their much smaller resorcinarene (1) counterparts, several derivatives were prepared. We demonstrate that (1) they are a suitable platform to synthesize large and wellsoluble cavitands, (2) derivatives of X-3 self-assemble to unusually large tetrameric supramolecular capsules, and (3) they enable the synthesis of a well-soluble oxygen-embedded zigzag hydrocarbon belt.

First, quinoxaline walls ${ }^{55}$ were introduced by nucleophilic aromatic substitution to deliver cavitand 23 in good yield (48\%, $88 \%$ yield per substitution, Scheme 2). 23 displays a high selectivity for binding adamantanemethanol (24) (see Supporting Information, Chapter 7.2). Interestingly, a series of other adamantane derivatives, ammonium salts, and fullerenes did not show uptake.

Second, derivatization at the upper rim of $\mathrm{X}-3$ was conducted in analogy to a literature procedure on resorcinarene. $^{56}$ After NBS-bromination (89\%) and subsequent permethylation $(88 \%)$, the aryl bromides were converted into phenolic moieties via halogen/lithium exchange, followed by quenching with trimethyl borate and subsequent oxidation. Product 25 was obtained in good yield considering that six positions were functionalized $(27 \%, 80 \%$ yield per functionality). Macrocycle 25 was characterized by ${ }^{1} \mathrm{H}$-, ${ }^{13} \mathrm{C}$-, and $2 \mathrm{D}$ NMR spectroscopy as well as ESI-HRMS measurements. In apolar solvents such as chloroform and toluene, 25 selfassembles to defined larger structures. Interestingly, this is in contrast to the unmodified X-3 and X-4 that did not form assemblies in apolar solvents. Whereas the signals of the ${ }^{1} \mathrm{H}$ NMR spectra are broad at room temperature, the signals sharpen upon cooling (Figure 2). At $228 \mathrm{~K}$, the phenol signals resonate as sharp peaks at 12.9 and $8.8 \mathrm{ppm}$, while the signals for the aromatic $\mathrm{C}-\mathrm{H}$ groups and the methoxy groups split into two sharp singlets each.

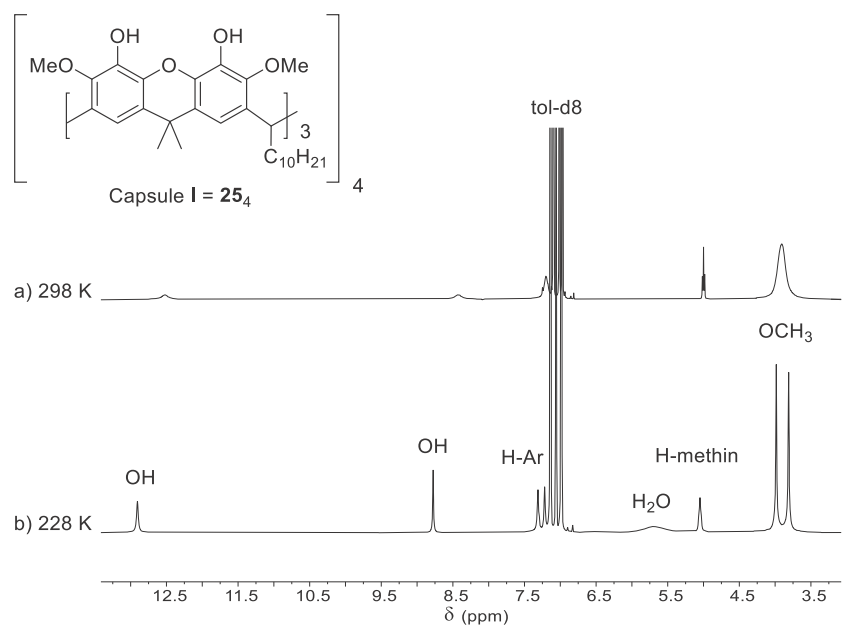

Figure 2. ${ }^{1} \mathrm{H}$ NMR spectra of capsule $I$ in toluene- $\mathrm{d}_{8}(1.25 \mathrm{mM})$ at (a) $298 \mathrm{~K}$ and (b) $228 \mathrm{~K}$

The geometric requirements of the C3-symmetric macrocycle 25 would, in principle, enable the self-assembly to dimeric, tetrameric, and octameric structures. These options can be differentiated via DOSY-NMR measurements. DOSYNMR has been established as a reliable tool for the size determination of supramolecular assemblies. ${ }^{57}$ This technique is very valuable as well-soluble derivatives usually do not crystallize well to enable X-ray structure determination. Moreover, the in-solution analysis is of high interest, as the crystal packing in the solid-state may change the assembly size and shape. DOSY-NMR experiments at $298 \mathrm{~K}$ in toluene- $\mathrm{d}_{8}$ provided a diffusion value of $D=0.23 \times 10^{-5} \mathrm{~cm}^{2} \mathrm{~s}^{-1}$. According to a well-established procedure involving the modified Stokes-Einstein equation, ${ }^{58}$ this value corresponds to a hydrodynamic radius of $r_{\mathrm{h}}=1.7 \mathrm{~nm}$ for the supramolecular assembly (see Supporting Information, Chapter 5.2). The hydrodynamic radius determined from the respective diffusion coefficient only correlates well with the molecular model of a tetrameric assembly $\left(r_{\text {dimer }}=1.30 \mathrm{~nm}, r_{\text {tetramer }}=1.6 \mathrm{~nm}, r_{\text {octamer }}\right.$ $=2.10 \mathrm{~nm}$, see Supporting Information, Chapter 5.3). Accordingly, the dimeric and octameric assembly can be reliably excluded. Additionally, substrate uptake studies with $\mathrm{C}_{60}$ and $\mathrm{C}_{70}$ fullerene provided further convincing evidence for the tetrameric size.

Molecular modeling clearly indicated that the dimeric capsule would be too small for uptake of either fullerene, while the tetrameric assembly would accommodate one $\mathrm{C}_{60}$ very well (see Supporting Information, Chapter 7.4). The octameric capsule on the other hand would easily accommodate several fullerenes at once. The experiments revealed (1) a selective uptake of $\mathrm{C}_{60}$, where no interactions with $\mathrm{C}_{70}$ were observed, and (2) that uptake was limited to 1 equiv of $\mathrm{C}_{60}$ (Figure 3, Supporting Information, 7.4). DOSY-NMR experiments further provided a diffusion value of $D=0.24 \times$ $10^{-5} \mathrm{~cm}^{2} \mathrm{~s}^{-1}$ for the host-guest complex, confirming the structural stability of assembly I upon guest uptake. The binding constant $K_{\mathrm{a}}$ was found to be approximately $7 \times 10^{5}$ $\mathrm{M}^{-1}$ (see Supporting Information, Chapter 7.4). Accordingly, the dimeric and octameric assembly can be reliably excluded based not only on the analysis of the diffusion value but also on this guest uptake study.

With an internal cavity volume of approximately $1400 \AA^{3}$, this tetrameric capsule $\mathbf{I}$ (Scheme $2 \mathrm{~b}$ ) is more than five times 
a) I

encapsulated $\mathrm{C}_{60}$

b) $\mathrm{I} \subset \mathrm{C}_{60}$

free $\mathrm{C}_{60}$

c) $\mathrm{C}_{60}$

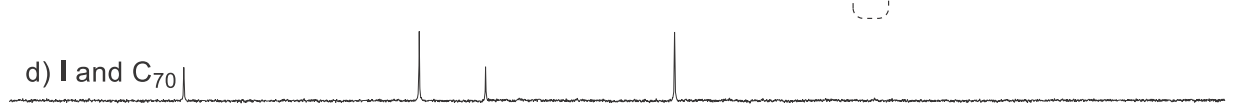

\begin{tabular}{|c|c|c|c|c|c|c|c|c|c|c|c|c|}
\hline e) $\mathrm{C}_{7}$ & & & & & & & & & & & & \\
\hline 152 & 151 & 150 & 149 & 148 & 147 & $\begin{array}{c}146 \\
\delta(\mathrm{ppm})\end{array}$ & 145 & 144 & 143 & 142 & 141 & 140 \\
\hline
\end{tabular}

Figure 3. ${ }^{13} \mathrm{C}$ NMR spectra in toluene- $\mathrm{d}_{8}$ of (a) capsule $\mathbf{I}(1.25 \mathrm{mM}),(\mathrm{b})$ capsule $\mathbf{I}$ and $\mathrm{C}_{60}$ fullerene (both $\left.0.85 \mathrm{mM}\right),(\mathrm{c}) \mathrm{C}_{60}(2.50 \mathrm{mM}),(\mathrm{d})$ capsule $\mathrm{I}$ and $\mathrm{C}_{70}$ (both $\left.0.85 \mathrm{mM}\right)$, and (e) $\mathrm{C}_{70}(1.00 \mathrm{mM})$.

larger than the largest tetrameric hydrogen bond-based supramolecular capsule reported so far $\left(270 \AA^{3}\right) .{ }^{59-61}$ Further guest uptake studies with alkyl ammonium guests indicated that the assembly displays a similar uptake behavior as the pyrogallol[4]arene (2) capsule with these guests. ${ }^{62}$ With $\mathrm{Et}_{4} \mathrm{NBr}$, a dimeric precipitate was observed. Dimeric assemblies of pyrogallolarene (2) containing ammonium species were previously observed to form in solid-state and as precipitates from solution. ${ }^{63-65}$ The addition of larger ammonium, terpene, and polyaromatic guests did not interfere with the formation of the tetrameric capsule. However, no host-guest complexes could be observed (see Supporting Information, Chapter 7.3).

Lastly, macrocycle 19 was converted to the $\mathrm{O}_{6}$-belt[12] arene 26 (Scheme 2c). This $O$-beltarene is 1.5 times wider than any previously reported $O$-derivative. The conversion was achieved using conditions reported recently on the resorcinarene (1) framework. $^{66}$ After triflation (99\%), a partial hydrolysis followed by aromatic substitution under basic reaction conditions yielded the $\mathrm{O}_{6}$-belt $[12]$ arene 26 in $76 \%$ isolated yield. The photophysical properties of $\mathbf{2 6}$ were investigated (Scheme 2c). The UV-vis absorption spectrum in $\mathrm{CH}_{2} \mathrm{Cl}_{2}$ at $293 \mathrm{~K}$ shows two bands with maxima at 227 and $275 \mathrm{~nm}(\varepsilon \approx$ 2500-6000 $\mathrm{M}^{-1} \mathrm{~cm}^{-1}$ ), which we attribute to spin-allowed transitions into singlet excited states. Furthermore, a broad (and considerably weaker) absorption feature between 300 and $375 \mathrm{~nm}$ is observed and is tentatively attributed to a spinforbidden transition into a triplet excited state. When a $\mathrm{CH}_{2} \mathrm{Cl}_{2}$ solution of $\mathrm{O}_{6}$-belt 26 is excited at $293 \mathrm{~K}$ at $275 \mathrm{~nm}$, a broad, featureless emission band with a maximum $\lambda_{\max , \text { em }}$ at $350 \mathrm{~nm}$ and a luminescence lifetime $\tau$ of $1.6 \mathrm{~ns}$ is observed. Emission measurements at $77 \mathrm{~K}$ in 2 -methyl-THF with excitation at 275 $\mathrm{nm}$ reveal some fine structure of this emission band, including progressions in a $\sim 1600 \mathrm{~cm}^{-1}$ mode (Scheme $2 \mathrm{c}$, right inset). Following excitation at $350 \mathrm{~nm}$, a weak emission band with a maximum at $462 \mathrm{~nm}$, which we attribute to phosphorescence, was observed (see Supporting Information, Chapter 8 for details). In cyclic voltammetry, no reduction or oxidation within the potential window between -2.2 and $1.9 \mathrm{~V} \mathrm{vs} \mathrm{Fc}^{+} / \mathrm{Fc}$ was detectable. This is in contrast to related $\mathrm{O}_{4}$-belt $[8]$ arenes which have been shown to undergo irreversible oxidation at a potential of $1.3 \mathrm{~V}$ vs $\mathrm{Fc}^{+} / \mathrm{Fc}^{66}$

In summary, we have developed a novel class of exceptionally large, conformationally restricted, bowl-shaped macro- cycles denoted xanthene $[n]$ arenes. The selective synthesis of xanthene[3] arenes or xanthene[4] arenes was achieved through modulation of the steric hindrance at the C9-position of the monomer (methyl, ethyl, n-propyl). The macrocycles are amenable to further modifications as demonstrated for X-3. Cavitand 23, hydrocarbon belt 26 , and macrocycle 25 , which is able to self-assemble to a tetrameric capsule, were synthesized in one, two, and three steps, respectively. Both supramolecular hosts displayed guest binding properties. Macrocycles with an intrinsic curvature are essential for the construction of closed container molecules like molecular capsules. Only very few suitable building blocks are available as of yet. Importantly, all available macrocycles are rather small with a diameter of approximately $7 \AA$ A. In contrast, the developed macrocycles X-3 and X-4 feature a diameter of 9.6 and even $14 \AA$, respectively. Conformationally restricted, bowl-shaped macrocycles of this size are unprecedented. Considering the current interest directed to the synthesis of novel macrocyclic hosts and selfassembling systems, we are convinced that they will serve as valuable platforms for the construction of a wide range of host structures, far beyond the examples we report in this Letter.

\section{ASSOCIATED CONTENT}

\section{Supporting Information}

The Supporting Information is available free of charge at https://pubs.acs.org/doi/10.1021/jacsau.1c00343.

Experimental details and NMR spectra of new compounds (PDF)

X-ray crystallographic data for $\mathbf{2 0}$ (CIF)

\section{Accession Codes}

CCDC 2108499 contains the supplementary crystallographic data for this paper. These data can be obtained free of charge via www.ccdc.cam.ac.uk/data request/cif, or by emailing data_request@ccdc.cam.ac.uk, or by contacting The Cambridge Crystallographic Data Centre, 12 Union Road, Cambridge CB2 1EZ, UK; fax: +44 1223336033.

\section{AUTHOR INFORMATION}

\section{Corresponding Author}

Konrad Tiefenbacher - Department of Chemistry, University of Basel, CH-4058 Basel, Switzerland; Department of Biosystems Science and Engineering, ETH Zürich, CH-4058 
Basel, Switzerland; 다이.org/0000-0002-3351-6121; Email: konrad.tiefenbacher@unibas.ch,tkonrad@ethz.ch

\section{Authors}

Jonathan Pfeuffer-Rooschüz - Department of Chemistry, University of Basel, CH-4058 Basel, Switzerland

Lucius Schmid - Department of Chemistry, University of Basel, CH-4058 Basel, Switzerland; 이잉.org/00000001-5803-6979

Alessandro Prescimone - Department of Chemistry, University of Basel, CH-4058 Basel, Switzerland; (1) orcid.org/0000-0002-3631-5210

Complete contact information is available at: https://pubs.acs.org/10.1021/jacsau.1c00343

\section{Author Contributions}

K.T. supervised and conceived the project. J.P.R. and K.T. planned the project. J.P.R. carried out all synthetic work and supramolecular studies. L.S. performed and interpreted the photophysical and electrochemical measurements of belt 26 . A.P. carried out the crystallographic analysis of 20 . The first draft of the manuscript was compiled by J.P.R. and K.T. All authors contributed to the final version of the manuscript.

Notes

The authors declare no competing financial interest.

\section{ACKNOWLEDGMENTS}

The generous support from the Swiss National Science Foundation (Grant SNF: 200021 178714) is gratefully acknowledged. We thank Prof. Oliver Wenger for his input regarding the photophysical and electrochemical measurements as well as Fabian Bissegger for VT-NMR experiments and Dr. Michael Pfeffer for HR-MS analysis.

\section{REFERENCES}

(1) Pedersen, C. J. Cyclic polyethers and their complexes with metal salts. J. Am. Chem. Soc. 1967, 89 (10), 2495-2496.

(2) Pedersen, C. J. Cyclic polyethers and their complexes with metal salts. J. Am. Chem. Soc. 1967, 89 (26), 7017-7036.

(3) Lehn, J. M. Cryptates: inclusion complexes of macropolycyclic receptor molecules. Pure Appl. Chem. 1978, 50 (9-10), 871.

(4) Lehn, J.-M. Supramolecular Chemistry: Receptors, Catalysts, and Carriers. Science 1985, 227 (4689), 849-856.

(5) Cram, D. J. The Design of Molecular Hosts, Guests, and Their Complexes (Nobel Lecture). Angew. Chem., Int. Ed. Engl. 1988, 27 (8), 1009-1020.

(6) Cram, D. J.; Cram, J. M. Container molecules and their guests; Royal Society of Chemistry, 1997.

(7) D’Souza, V. T.; Lipkowitz, K. B. Cyclodextrins: Introduction. Chem. Rev. 1998, 98 (5), 1741-1742.

(8) Crini, G. A history of cyclodextrins. Chem. Rev. 2014, 114 (21), 10940-10975.

(9) Assaf, K. I.; Nau, W. M. Cucurbiturils: from synthesis to highaffinity binding and catalysis. Chem. Soc. Rev. 2015, 44 (2), 394-418.

(10) Liu, Z.; Nalluri, S. K. M.; Stoddart, J. F. Surveying macrocyclic chemistry: from flexible crown ethers to rigid cyclophanes. Chem. Soc. Rev. 2017, 46 (9), 2459-2478.

(11) Cram, D. J. Cavitands: Organic Hosts with Enforced Cavities. Science 1983, 219 (4589), 1177-1183.

(12) Biros, S. M.; Rebek, J. J. Structure and binding properties of water-soluble cavitands and capsules. Chem. Soc. Rev. 2007, 36 (1), 93-104.

(13) Collet, A. Cyclotriveratrylenes and cryptophanes. Tetrahedron 1987, 43 (24), 5725-5759.
(14) Jasat, A.; Sherman, J. C. Carceplexes and Hemicarceplexes. Chem. Rev. 1999, 99 (4), 931-968.

(15) Warmuth, R.; Yoon, J. Recent Highlights in Hemicarcerand Chemistry. Acc. Chem. Res. 2001, 34 (2), 95-105.

(16) Ajami, D.; Rebek, J. More Chemistry in Small Spaces. Acc. Chem. Res. 2013, 46 (4), 990-999.

(17) Yu, Y.; Rebek, J. Reactions of Folded Molecules in Water. Acc. Chem. Res. 2018, 51 (12), 3031-3040.

(18) Lawrence, D. S.; Jiang, T.; Levett, M. Self-Assembling Supramolecular Complexes. Chem. Rev. 1995, 95 (6), 2229-2260.

(19) Conn, M. M.; Rebek, J. Self-Assembling Capsules. Chem. Rev. 1997, 97 (5), 1647-1668.

(20) de Mendoza, J. Self-Assembling Cavities: Present and Future. Chem. - Eur. J. 1998, 4 (8), 1373-1377.

(21) Jin, P.; Dalgarno, S. J.; Atwood, J. L. Mixed metal-organic nanocapsules. Coord. Chem. Rev. 2010, 254 (15-16), 1760-1768.

(22) Kobayashi, K.; Yamanaka, M. Self-assembled capsules based on tetrafunctionalized calix[4]resorcinarene cavitands. Chem. Soc. Rev. 2015, 44 (2), 449-466.

(23) Jordan, J. H.; Gibb, B. C. Molecular containers assembled through the hydrophobic effect. Chem. Soc. Rev. 2015, 44 (2), 547585 .

(24) Ajami, D.; Liu, L.; Rebek, J., Jr Soft templates in encapsulation complexes. Chem. Soc. Rev. 2015, 44 (2), 490-499.

(25) Gutsche, C. D. Calixarenes. Acc. Chem. Res. 1983, 16 (5), 161170.

(26) Gutsche, C. D.; Rogers, J. S.; Stewart, D.; See, K.-A. Calixarenes: paradoxes and paradigms in molecular baskets. Pure Appl. Chem. 1990, 62 (3), 485.

(27) Böhmer, V. Calixarenes, Macrocycles with (Almost) Unlimited Possibilities. Angew. Chem., Int. Ed. Engl. 1995, 34 (7), 713-745.

(28) Timmerman, P.; Verboom, W.; Reinhoudt, D. N. Resorcinarenes. Tetrahedron 1996, 52 (8), 2663-2704.

(29) Tunstad, L. M.; Tucker, J. A.; Dalcanale, E.; Weiser, J.; Bryant, J. A.; Sherman, J. C.; Helgeson, R. C.; Knobler, C. B.; Cram, D. J. Host-guest complexation. 48. Octol building blocks for cavitands and carcerands. J. Org. Chem. 1989, 54 (6), 1305-1312.

(30) Shorthill, B. J.; Glass, T. E. Naphthalene-Based Calixarenes: Unusual Regiochemistry of a Friedel-Crafts Alkylation. Org. Lett. 2001, 3 (4), 577-579.

(31) Georghiou, P. E.; Li, Z.; Ashram, M.; Chowdhury, S.; Mizyed, S.; Tran, A. H.; Al-Saraierh, H.; Miller, D. O. Calixnaphthalenes: Deep, Electron-Rich Naphthalene Ring-Containing Calixarenes. The First Decade. Synlett 2005, 2005 (06), 0879-0891.

(32) Shorthill, B. J.; Granucci, R. G.; Powell, D. R.; Glass, T. E. Synthesis of 3,5- and 3,6-Linked Calix[n]naphthalenes. J. Org. Chem. 2002, 67 (3), 904-909.

(33) Yang, L.-P.; Liu, W.-E.; Jiang, W. Naphthol-based macrocyclic receptors. Tetrahedron Lett. 2016, 57 (36), 3978-3985.

(34) Chen, H.; Fan, J.; Hu, X.; Ma, J.; Wang, S.; Li, J.; Yu, Y.; Jia, X.; Li, C. Biphen[n]arenes. Chem. Sci. 2015, 6 (1), 197-202.

(35) Yang, P.; Jian, Y.; Zhou, X.; Li, G.; Deng, T.; Shen, H.; Yang, Z.; Tian, Z. Calix[3]carbazole: One-Step Synthesis and Host-Guest Binding. J. Org. Chem. 2016, 81 (7), 2974-2980.

(36) Zhang, G.-W.; Li, P.-F.; Meng, Z.; Wang, H.-X.; Han, Y.; Chen, C.-F. Triptycene-Based Chiral Macrocyclic Hosts for Highly Enantioselective Recognition of Chiral Guests Containing a Trimethylamino Group. Angew. Chem., Int. Ed. 2016, 55 (17), 5304-5308.

(37) Chen, C.-F.; Han, Y. Triptycene-Derived Macrocyclic Arenes: From Calixarenes to Helicarenes. Acc. Chem. Res. 2018, 51 (9), 20932106.

(38) Della Sala, P.; Del Regno, R.; Talotta, C.; Capobianco, A.; Hickey, N.; Geremia, S.; De Rosa, M.; Spinella, A.; Soriente, A.; Neri, P.; Gaeta, C. Prismarenes: A New Class of Macrocyclic Hosts Obtained by Templation in a Thermodynamically Controlled Synthesis. J. Am. Chem. Soc. 2020, 142 (4), 1752-1756.

(39) Han, X.-N.; Han, Y.; Chen, C.-F. Pagoda[4]arene and iPagoda[4]arene. J. Am. Chem. Soc. 2020, 142 (18), 8262-8269. 
(40) Du, X.-S.; Zhang, D.-W.; Guo, Y.; Li, J.; Han, Y.; Chen, C.-F. Towards the Highly Efficient Synthesis and Selective Methylation of C(sp3)-Bridged [6]Cycloparaphenylenes from Fluoren[3] arenes. Angew. Chem., Int. Ed. 2021, 60 (23), 13021-13028.

(41) Han, X.-N.; Zong, Q.-S.; Han, Y.; Chen, C.-F. Pagoda[5]arene with Large and Rigid Cavity for the Formation of 1:2 Host-Guest Complexes and Acid/Base-Responsive Crystalline Vapochromic Properties. CCS Chem. 2021, 3 (1), 738-750.

(42) Wang, M.-X. Heterocalixaromatics, new generation macrocyclic host molecules in supramolecular chemistry. Chem. Commun. 2008, No. 38, 4541-4551.

(43) Ogoshi, T.; Kanai, S.; Fujinami, S.; Yamagishi, T.-a.; Nakamoto, Y. para-Bridged Symmetrical Pillar[5]arenes: Their Lewis Acid Catalyzed Synthesis and Host-Guest Property. J. Am. Chem. Soc. 2008, 130 (15), 5022-5023.

(44) Xue, M.; Yang, Y.; Chi, X.; Zhang, Z.; Huang, F. Pillararenes, A New Class of Macrocycles for Supramolecular Chemistry. Acc. Chem. Res. 2012, 45 (8), 1294-1308.

(45) Jia, F.; He, Z.; Yang, L.-P.; Pan, Z.-S.; Yi, M.; Jiang, R.-W.; Jiang, W. Oxatub[4] arene: a smart macrocyclic receptor with multiple interconvertible cavities. Chem. Sci. 2015, 6 (12), 6731-6738.

(46) Ogoshi, T.; Yamagishi, T.-a.; Nakamoto, Y. Pillar-Shaped Macrocyclic Hosts Pillar[n]arenes: New Key Players for Supramolecular Chemistry. Chem. Rev. 2016, 116 (14), 7937-8002.

(47) Wu, J.-R.; Yang, Y.-W. New opportunities in synthetic macrocyclic arenes. Chem. Commun. 2019, 55 (11), 1533-1543.

(48) Yang, W.; Samanta, K.; Wan, X.; Thikekar, T. U.; Chao, Y.; Li, S.; Du, K.; Xu, J.; Gao, Y.; Zuilhof, H.; Sue, A. C.-H. Tiara[5]arenes: Synthesis, Solid-State Conformational Studies, Host-Guest Properties, and Application as Nonporous Adaptive Crystals. Angew. Chem., Int. Ed. 2020, 59 (10), 3994-3999.

(49) Konishi, H.; Ohata, K.; Morikawa, O.; Kobayashi, K. Calix[6]resorcinarenes: the first examples of [16]metacyclophanes derived from resorcinols. J. Chem. Soc., Chem. Commun. 1995, No. 3, 309-310.

(50) Konishi, H.; Nakamura, T.; Ohata, K.; Kobayashi, K.; Morikawa, O. The acid-catalyzed condensation of 2-propylresorcinol with formaldehyde diethyl acetal. The formation and isomerization of calix[4]resorcinarene, calix[5]resorcinarene, and calix[6]resorcinarene. Tetrahedron Lett. 1996, 37 (41), 7383-7386.

(51) Naumann, C.; Román, E.; Peinador, C.; Ren, T.; Patrick, B. O.; Kaifer, A. E.; Sherman, J. C. Expanding Cavitand Chemistry: The Preparation and Characterization of [n]Cavitands with $n \geq 4$. Chem. Eur. J. 2001, 7 (8), 1637-1645.

(52) Purse, B. W.; Shivanyuk, A.; Rebek, J. Resorcin[6]arene as a building block for tubular crystalline state architectures. Chem. Commun. 2002, No. 22, 2612-2613.

(53) Chwastek, M.; Szumna, A. Higher Analogues of Resorcinarenes and Pyrogallolarenes: Bricks for Supramolecular Chemistry. Org. Lett. 2020, 22 (17), 6838-6841.

(54) Hanousek, V. Nebenprodukte der Fluoreszeinschmelze. Collect. Czech. Chem. Commun. 1959, 24, 1061-1073.

(55) Moran, J. R.; Karbach, S.; Cram, D. J. Cavitands: synthetic molecular vessels. J. Am. Chem. Soc. 1982, 104 (21), 5826-5828.

(56) Merget, S.; Catti, L.; Piccini, G.; Tiefenbacher, K. Requirements for Terpene Cyclizations inside the Supramolecular Resorcinarene Capsule: Bound Water and Its Protonation Determine the Catalytic Activity. J. Am. Chem. Soc. 2020, 142 (9), 4400-4410.

(57) Avram, L.; Cohen, Y. Diffusion NMR of molecular cages and capsules. Chem. Soc. Rev. 2015, 44 (2), 586-602.

(58) Chen, H. C.; Chen, S. H. Diffusion of crown ethers in alcohols. J. Phys. Chem. 1984, 88 (21), 5118-5121.

(59) Martín, T.; Obst, U.; Rebek, J. Molecular Assembly and Encapsulation Directed by Hydrogen-Bonding Preferences and the Filling of Space. Science 1998, 281 (5384), 1842-1845.

(60) Hof, F.; Nuckolls, C.; Craig, S. L.; Martín, T.; Rebek, J. Emergent Conformational Preferences of a Self-Assembling Small Molecule: Structure and Dynamics in a Tetrameric Capsule. J. Am. Chem. Soc. 2000, 122 (44), 10991-10996.
(61) Baillargeon, P.; Dory, Y. L. Rational Design and Gas-Phase Characterization of Molecular Capsules by Self-Assembly of a Symmetric Hexasubstituted Benzene with Seven-Membered Lactams. J. Am. Chem. Soc. 2008, 130 (17), 5640-5641.

(62) Zhang, Q.; Catti, L.; Kaila, V. R. I.; Tiefenbacher, K. To catalyze or not to catalyze: elucidation of the subtle differences between the hexameric capsules of pyrogallolarene and resorcinarene. Chem. Sci. 2017, 8 (2), 1653-1657.

(63) Shivanyuk, A.; Friese, J. C.; Döring, S.; Rebek, J. SolventStabilized Molecular Capsules. J. Org. Chem. 2003, 68 (17), 64896496.

(64) Åhman, A.; Luostarinen, M.; Rissanen, K.; Nissinen, M. Complexation of C-methyl pyrogallarene with small quaternary and tertiary alkyl ammonium cations. New J. Chem. 2007, 31 (1), 169177.

(65) Beyeh, N. K.; Rissanen, K. Dimeric Resorcin[4]arene Capsules in the Solid State. Isr. J. Chem. 2011, 51 (7), 769-780.

(66) Tan, M.-L.; Guo, Q.-H.; Wang, X.-Y.; Shi, T.-H.; Zhang, Q.; Hou, S.-K.; Tong, S.; You, J.; Wang, M.-X. Oxygen- and NitrogenEmbedded Zigzag Hydrocarbon Belts. Angew. Chem., Int. Ed. 2020, 59 (52), 23649-23658. 